\title{
Colette Bridgman: 'The two prototype practices in Wales have been a sensational success'
}

\author{
Interview by David Westgarth
}

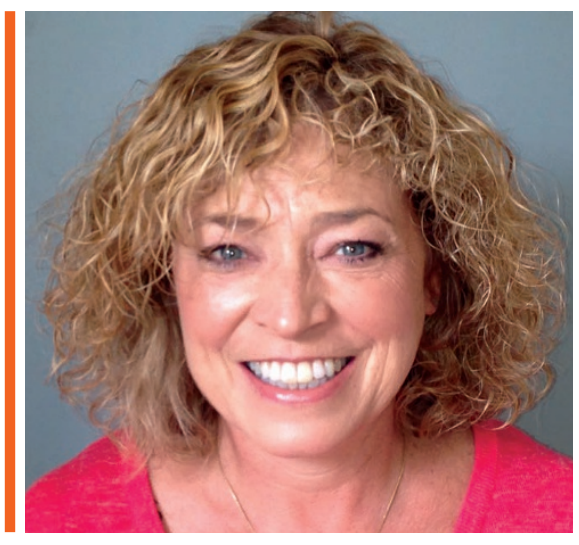

\section{What have you learned in your first six months?}

I used the first couple of months to familiarise myself with how the Welsh Government operates, getting to know the Deputy CDO, other professional leads and the senior civil servants in Dental Branch. Coming from England where I was embedded in NHS England but employed by Public Health England (PHE) and somewhat removed from government, it was a very different experience. During this induction period I met with key NHS and government personnel to learn about their roles and interests. I took the opportunity to discuss the relevance of dentistry and oral health's importance to their agendas, which was well received. Within health service delivery and public health, oral health and dentistry is important to policy and political leaders in Wales. Those things combined have given me a platform from which to work from.

Around the time I took up the position the new government came in, and within six weeks they'd published their 5-year programme for government called 'Taking Wales Forward'. This focusses on delivering real improvement in every day lives and improving the Welsh economy. It acknowledges that improved health and well-being will underpin their ambition. I know that improving oral health and dental services will contribute to their plan for Wales.

\section{In August 2016, Dr Colette Bridgman left her role in Greater Manchester to} take up office as the Chief Dental Officer (CDO) for Wales. Six months into the role, BDJ In Practice editor David Westgarth caught up with Dr Bridgman to find out what challenges lie ahead.

Having worked for a number of years in Greater Manchester (GM), which was establishing a devolved administration, I understand the complexities and associated challenges in getting oral health onto the agenda. Coming here to a more mature devolved administration - and by mature I mean one that has been established, has ironed out kinks in the road and is now seeing the benefit of devolution - I realised very quickly oral health wasn't just on the agenda but an important and integrated part of it.

\section{So how will your time in Manchester assist the Welsh population now?}

There are similarities between the two, which on a personal level is incredibly useful to benchmark progress. Both have a similar population size of around 3 million, similar social gradients and similar numbers of dental practices and specialist services; because of those things many of the oral health and service challenges are familiar. The noticeable difference is the vast geography of Wales together with culture, language and areas of outstanding natural beauty! Best of all, in dental terms, Wales has an established, successful population oral health scheme which is delivering improvement in young children.

There is a collegiate way of working across dental organisations and structures here in Wales. There is respect and a voice for the different roles within dentistry. There is capacity, talent and enthusiasm to make a difference and collectively they have achieved getting oral health onto the agenda. Manchester's devolution process is underway, Wales has had a head start, it's exciting to come into that arena!

My predecessor David Thomas led the development of the National Oral Health Plan for Wales. It is due a refresh but I'm working in an office that has five years of working to that plan under their belts. Progress isn't going to be about wholesale change, but adding value.

Within the first three months I was asked to provide, and have just completed, advice to the Cabinet Secretary setting out our priorities for the coming year. 'Taking Oral Health Improvement and Dentistry Forward' sets the direction and intentions going forward so that clinical and health board teams can contribute constructively and cohesively. This work will inform a planned refresh of the National Oral Health Plan expected later this year.

Some of the biggest successes we had in GM were as a result of stimulating innovation through developing clinical leadership, particularly within GDPs. Some of the work is highly regarded in England today and has influenced national policies. GDS Teams in Salford and Oldham developed and tested collecting and using oral health needs/risk assessment in NHS dental practices. They developed preventive care pathways, with integrated self care, measured by outcomes. Their learning was cited in the 
Independent Review of NHS Dentistry and informed the pilot programme. The same practitioners started to understand the balance between need and demand, and that every patient was different. One size would not fit all. Some of them have gone on to lead improvements, through local professional networks. That's one area I know I can add value to in Wales. I want to get GDS dentists and their teams involved in new ways of working and contributing to primary care clusters.

Having got to grips with some of the high level issues, I can now focus on meeting teams on the ground and how I can stimulate that clinical leadership development. The Cluster Programme mirrors some of the local professional network approach.

With some of the contract reform work we've started, the enthusiasm, commitment and determination to take part shows me the profession will be co-producing the final products, whatever form they take. The majority of clinicians in dentistry work in general dental practice and I want them to have a voice, to have a chance to influence new ways of working and equip them to make changes. Healthy Gums Do Matter, a periodontology resource produced by GDPs for GDPs in GM, is a great example of what can be achieved when that process comes together. I have already been asked 'when are we going to have this perio resource in Wales?'

\section{What is it about current innovations and ones you've previously established that makes them successful?}

There is a tendency to overcomplicate things. Designed to Smile is a straightforward project based on elements of Childsmile. It targets getting fluoride on the teeth of young children, particularly in deprived areas, through the application of varnish and by facilitating supervised daily brushing; it has been replicated across Wales. There's another project in GM involving a dentist and a doctor collaborating on getting the right care pathway for children attending A\&E for dental problems. You have to look at what simple and sure steps can take us forward. I have a vision for Wales that involves supporting clinicians in primary dental care to try new ways of working. I want to develop their understanding of the needs of patients and agree how we can record that, deliver appropriate care and measure change. The mouth is a part of the body and clinical teams need to take account of clinical needs, lifestyle behaviour and literacy levels of patients so that oral health messages are understood and can be acted on. Healthy Gums Do Matter is an excellent example of clinicians leading change that impacted positively on patient outcomes and also facilitated system change.

\section{'Putting the mouth back in the body' is a favourite quote of Dr Sara Hurley. What can you - and have you - learned from Sara's first 18 months in post?}

I know England is a complex system and Sara has her work cut out for her. One thing Sara did that I really admired was to 'get out and meet people' across regions in England. I want to get out more and meet clinical and Health Board teams in Wales. Having said that, I can't go out without knowing what issues are out there, what responses you may or may not get. It's important for me to look at the success and challenges we've had in Wales with fresh eyes. Take Designed to Smile for example. I want to door there's a tangible feeling of success. They are well-run, preventively-focused patientcentred services. The question for me - and for all of us - is how can we replicate this across the country? Interestingly, some of the practices originally involved in the pilot programme in Wales had to revert, which is a shame as we need more than two successful practices for this to become an implemented strategy. Many of those who had to revert felt demoralised returning to UDAs, which tells its own story.

We have to take these lessons on board. There is a wealth of potential by getting practices involved with what I'm calling contract reform, and I hope that those who do get involved will help to form and inform the shape of a new contract.

Clearly we don't want to limit the prototypes to two practices. We are engaging with the wider dental community, contract

\section{'The Cabinet Secretary['s] message is loud and clear: it must be done at a pace and scale that will make a difference'}

know what is working well. What has really contributed to the $12 \%$ point improvement in the oral health of our five-year-olds? By doing this, you can share and build on that success. I want it to go from 'good to great'.

It also gives me the platform to lift the project beyond dentistry. Designed to Smile has been imbedded successfully among community dental services, and I believe it's time for GDPs and others to take up the mantle and get involved. We can share the key messages and actions required with our allies in healthcare and education so that they too can put their shoulder to the wheel and help to deliver further improvements.

When you get a $12 \%$ point improvement it becomes harder in some communities to find the 'pockets' with the greatest need. That is where GDPs, their teams and medical colleagues can assist and engage with us.

\section{You mention looking at current projects and policies with fresh eyes, so how do you see the contract reform and prototypes?}

What is undeniable is there's an awful lot we can be doing, without the need for a new contract, to enable dentists to work in new ways. The two prototype practices in Wales have been a sensational success. The minute you walk in the managers and health boards to ensure we continue to move forward. The Cabinet Secretary understands there is more we could be doing now, and his message is loud and clear: it must be done at a pace and scale that will make a difference.

It all starts with an understanding of patient needs. The message coming from GDPs is they don't want us to be over-prescriptive - they know how to manage care. They want support in what they are already doing. We have done incredibly well in Wales getting patients through the doors and equipping them with preventive advice, and in some respects a little too well. Those coming through the doors appear to be doing so too often for their needs, perhaps denying timely access for those with greater needs, but these 'well' patients do assist a practice to achieve their UDA target. Until we have a substantial evidence base and needs assessment, this remains anecdotal advice from those on the ground.

We will continue to use the prototype practices to collect data at regular intervals in order to inform our thinking. We need to find ways to measure good delivery in primary dental care, how a new contract could be measured, beyond UDAs which are firmly entrenched at the moment. Whatever happens, we are looking at contract reform 
this year, not a new contract per se. If, for example, we took a percentage of UDAs from a contract - $10 \%$ - that could allow a team to focus on an outreach project or to offer access and care to an identified group for one session a week 'without a UDA target'. That may work for some practices. Others may prefer to spread 'a relaxation of UDA target' over the course of a contract year and agree to collect need and outcome data. Perhaps we need a menu that health boards and dentists can choose from and test across different areas of Wales to see what works. Menus of service level agreements that work for patients, dentists and health boards to flex the boundaries of the current contract is definitely one area to explore.

\section{How does Wales' rurality affect the delivery of dental care?}

We are working to improve our understanding of the challenges dental services in rural areas in particular face. These challenges are quite complex in nature and are often underpinned by geographical issues, such as transport. Practice owners do have issues recruiting in the rural areas of the country. Younger dentists want to be in more urban and more populated areas. We are confident that the new contracting mechanism will help rural dental services. How many specialist dental services have issues with patients attending appointments? Can those specialist providers flip the coin and travel to offer care nearer home for the patient? I am used to innovative solutions, but I do not underestimate the challenge. There are bursaries available for those wishing to train in Wales and ply their trade here for a certain amount of time. Innovations like this are important with student fees as they are.

\section{Every challenge presents an opportunity. Where do you see the biggest opportunity for improvement in Wales?}

During my time in Greater Manchester I learned that challenges often present situations that can drive innovative thinking. Given the recruitment challenges in rural areas, one of the biggest opportunities Wales has grasped is to make direct access work. Welsh dental teams have embraced it. Community dental services tested it, made it work and we see the results with significantly more children receiving primary dental care than might otherwise have done so. What's more, dental care professionals are putting themselves in a position to become leaders by sharing experiences of innovative good practice.
One practice owner I have spoken to is leading a team with enhanced skills dental nurses trained and competent in applying fluoride varnish, making radiographs, doing plaque scores and offering preventive advice. It is a sophisticated use of skill mix that also includes hygienists and therapists. This dentist has been able to pursue other interests and improved practice profitability. It is a financially viable model and a great example of how it can work.

Their embrace of skill mix is in large part being driven by a strategy in Wales called Prudent Healthcare, part of the fairer healthcare for all. There are four principles:

- Achieve health and wellbeing with patients and professionals as equal partners

- Care for those with the greatest health need first, making the most effective use of skills

- Do only what is needed, no more, no less; and do no harm

- Reduce inappropriate variation using evidence-based practices.

The strategy talks about co-production, so whatever you do is in agreement with the patient, and treat those with the highest needs first. Underpinning the whole strategy is addressing inequality at the level you can do it and doing what only you can do.

Naturally this opens the door to building skill mix, to developing dental care professionals and, given the strategic context of Prudent Healthcare, we could have more dentists in leadership roles, with teams delivering more care of a higher quality to more people.

\section{How do associates fit into this picture in Wales?}

Given the access and recruitment issues mentioned, dental body corporates are a significant part of the market in Wales and we are in regular dialogue, which is very welcome. The drawback some health boards report is that they do see more staff turnover and less stability than in a traditional practice ownership model. There are a number of difficulties we will look to address, and we need to ensure Wales is an attractive place to work. Through contract reform there are opportunities to support dentists to come to Wales and see it as an attractive place to work. When you don't have large urban areas people do tend to take some time assessing what they want from their career and lives. Understandably younger people want to work for larger practices and corporate bodies rather than in smaller practices where they may feel isolated. Students are almost driven into a salaried situation with their level of debt from university and many have several part-time roles, which is far from ideal.

\section{Taking all of these things into account, what can we expect to see from you moving forward?}

My main task is to deliver a framework to give Together for Health: A National Oral Health Plan for Wales a refresh. I have set out my three priorities for the coming year, and they are a re-focus of Designed to Smile, movement on contract reform so more practices can experience better ways of working, and more connectivity in dentistry. My experience of making progress from my time in Greater Manchester will help me build what I want to see within the National Oral Health Plan. The current plan delivered a $12 \%$ point improvement in children's oral health. Now we're at the $35 \%$ of 5 -year-old children affected by decay mark, we can start to articulate that virtually eradicating decay in young children is a realistic option. That figure previously stood a little over half; now we can be ambitious in what we want to achieve.

It will be important to take account of the changing needs. Wales has a large ageing population, so it will be prudent to see oral health improvement and dental care planning aligned. People retaining their teeth for longer is a success but that opens new challenges, such as patients with co-morbidities and complex dental needs, especially in the older generation. Our workforce needs to be equipped to deal with those needs and to be proactive now with a preventive approach.

Beyond that the next biggest interest group is young adults. In 2013, 63\% of 15-year-olds in Wales had active decay. These are now 18-year-olds. These are the people Wales wants to be healthier, active and engaged to improve the economy. They will be the ones the Taking Wales Forward programme is aimed at. We have to take an interest in this group to understand their needs and expectations of dental services. They will become parents and will influence the oral health of their children. We have to ensure they have, and can act, on the right information to ensure the next generation is better equipped to protect oral health. If I can leave a legacy, not of change, but of adding value to current work, by building capacity in clinical leadership and making greater use of the skills of the whole team, I would certainly think the oral health of the nation would be in better shape. 